$1-1-2012$

\title{
A Structural Guide To In-Depth Interviewing In Business And Industrial Marketing Research
}

\author{
Elad Granot \\ Cleveland State University, e.granot@csuohio.edu \\ Thomas Brashear Alejandro \\ University of Massachusetts - Amherst \\ Paulo Cesar Motta \\ Pontificia Catolica Universidade do Rio De Janeiro
}

Follow this and additional works at: https://engagedscholarship.csuohio.edu/bus_facpub

Part of the Marketing Commons

How does access to this work benefit you? Let us know!

Publisher's Statement

This is the Author Accepted Manuscript version of A Structural Guide To In-Depth Interviewing In Business and Industrial Marketing Research, published in the Journal of Business \& Industrial Marketing, 27, 7, http://dx.doi.org/10.1108/08858621211257310

\section{Original Published Citation}

Granot, E., Brashear, T.G., \& Motta, P.C. (2012). A structural guide to in-depth internviewing in business and industrial marketing research. Journal of Business \& Industrial Marketing, 27(7), 547-553. doi:10.1108/ 08858621211257310

This Article is brought to you for free and open access by the Monte Ahuja College of Business at EngagedScholarship@CSU. It has been accepted for inclusion in Business Faculty Publications by an authorized administrator of EngagedScholarship@CSU. For more information, please contact library.es@csuohio.edu. 


\title{
A structural guide to in-depth interviewing in business and industrial marketing research
}

\author{
Elad Granot \\ Department of Marketing, Cleveland State University, Cleveland, Ohio, USA \\ Thomas G. Brashear \\ Department of Marketing, University of Massachusetts Amherst - Eugene M. Isenberg School of Management, Amherst, \\ Massachusetts, USA, and \\ Paulo Cesar Motta \\ Pontificia Catolica Universidade do Rio de Janeiro - IAG Business School, Rio de Janeiro, Brazil
}

\begin{abstract}
Purpose - The authors aim to present a structural guide for data collection in a participant-oriented, B2B context.

Design/methodology/approach - A three-stage interview process following the work of Seidman is presented, along with key issues on how to plan, structure, and execute a B2B interview-based hermenuetic ethnographic study.

Research limitations/implications - The framework presented in this paper provides strong theoretical foundation for further theory development in global industrial marketing research and managerial cognition research. However, given the conceptual nature of the research, empirical scrutiny and further conceptual and empirical research are required.

Originality/value - There is a serious gap in the literature when addressing the issue of B2B contextual studies, focusing on managers, manufacturers, and various other professional personnel.
\end{abstract}

Keywords Qualitative methods, In-depth interviewing, Hermeneutics, Phenomenology, Ethnography, Research methods, Interviews

Paper type Technical paper

\section{Introduction}

In the marketing academic community in general, and in $\mathrm{B} 2 \mathrm{~B}$ research in particular, the dominant scientific method is onesided and predominantly utilizes the deductive hypothesestesting approach (Hunt, 2002). In any research situation, it is vital that the "problem" dictate the selection of a methodology adopted, rather than the reverse where the methodology must adapt itself to the "problem" While statistical data are considered to be most useful when there is a need to identify the specific magnitude of a problem or issue (Dervin and Clark, 1987), qualitative data are of greater value in the identification of underlying causes, as well as the understanding of the processes. In a discipline as applied as marketing, qualitative methods enable a deeper understanding of behavior, rather than a shallow representation of intentions. This paper is based on the tenet that interpretive methodologies are appropriate to cope with market strategy formation in dynamic market settings. Hence, we provide a structural tool for researchers who consider a methodology that seeks to elicit information regarding both the needs and motivations of the participants and potential uses of the resource that is being investigated, as a means of informing and providing support to researchers and practitioners.

In conducting qualitative exploratory marketing studies, Fournier and Mick (1999) advocate serving a provocative role in mature research by distancing from historically dominant paradigms to question, revitalize, and redirect research along emergent lines. They suggest that data collection and analysis be performed with careful attention given to sociocultural and personal lived experiences, thus allowing for representation of context and meaning in participants' experiences. However, this application of a hermeneutic phenomenology is usually found in studies about consumers, as opposed to managers and other professionals who more typically represent participants in a $\mathrm{B} 2 \mathrm{~B}$ context. A qualitative study, in any variation (B2B or B2C), is fundamentally exploratory in nature (Seidman, 1998). If, indeed, research aims to better understand a phenomenon, the qualitative paradigm is more efficient and inherently designed to provide an initial groundbreaking, theory-building explanation (Woodside and Wilson, 2003).

The challenge in $\mathrm{B} 2 \mathrm{~B}$ marketing research is in how to incorporate ethnographic storytelling into the discipline. Participant narratives can be utilized to distill a richer understanding of that which is to be investigated. We therefore answer the call to advance the hermeneutical framework (Arnold and Fischer, 1994) by providing it with an applied extension for B2B research. The principal objective here is to provide a guide for applied data collection for achieving deeper sense-making of what happened and why it happened - including how participants interpret outcomes of what happened and the dynamics of emic and etic sensemaking. 
As a grounding theoretical framework, we adopt theories developed by cognitive anthropologists such as Strauss and Quinn (1997), D’Andrade (1981), Colby (1996) and Tyler (1969). Hermeneutic phenomenology, as interpreted by Van Manen (1990) and developed by Shütz and Luckman (1973), is used as a theoretical knowledge base. Most importantly, indepth interviewing, as described and prescribed by Seidman (1998), is adapted into a B2B marketing research context. Although these forms of inquiry are diverse (Spiegelberg, 1982, pp. 1-19; Zaner and Ihde, 1973, pp. 333-74), there exist within these diversities some fundamental and shared principles, which form its basic "infrastructure". These principles include an interest in understanding the phenomena of interest from the "inside", in the study of the life world, in comprehending the meaning of everyday experiences and in providing trustworthy insights of our "social" world. As the concept is used here, hermeneutic phenomenological human science is interested in the human world as we find it in all its diverse aspects. Unlike other research approaches in marketing that may make use of experimental or artificially created test situations, our approach to human science wishes to meet human beings participants - where they are naturally engaged in their worlds.

This paper is also based on the epistemological premises that $\mathrm{B} 2 \mathrm{~B}$ markets are socially constructed and thus that business market players and entities enact their environments (Starbuck, 1982; Weick, 1979; Strati, 1998; Sutcliffe and Huber, 1998). We propose that researchers should therefore employ a methodology that enables the study of participants' cognitions and changes in these cognitions. Our aim is to grasp the processes of the formation of participant preferences and how these preferences dictate behavior. We begin with a brief overview of the framework for an interview-based B2B phenomenological ethnography. This is followed by an explication of the three-stage interview process. The next sections focus on key issues in the interview process, the length of the three-stage process, the validity of the process, and the practice of interviewing. The hermeneutic data collection section provides a guide with various recommendations on the appropriate application of the three-stage interview process. The paper ends with conclusions and final comments focusing on the maintenance of the structure and possible methodological flexibility in the proposed process.

\section{B2B phenomenological ethnography}

While interpretive methods have long been accepted as valid and efficient in consumer research, B2B research, with its inherent relevance to managers, has not shared this acceptance. However, we contend that most discoveryoriented projects' goals (especially if they are B2B) dictate the use of ethnographic, phenomenological interviewing over more structured approaches to inquiry. By permitting an understanding of the subjective meanings of participants' lived professional experiences, the technique is better suited for establishing validity of research propositions.

In addition, an interpretive research approach is appropriate for more actionable and more relevant prescriptions to managers (Starkey and Madan, 2001). In fact, interpretive research methods allow for explanations that are highly contextualized and that lead to actionable recommendations and prescriptions, a characteristic that is crucial to business markets. That way, an interpretive methodology might be one of the pillars that help bridge the so-called relevance gap (Starkey and Madan, 2001; Weick, 2001) between academic theories and managerial practice. As early as 1973, Jackson Grayson phrased the problem of lack of relevance in the following way:

... management science has grown so remote from and unmindful of the conditions of "live" management that it has abdicated its usability. [...] Managers and management scientists are operating as two separate cultures, each with its own goals, languages, and methods (Grayson, 1973, p. 41).

Researchers can use a variety of techniques to collect data. A marketing researcher may choose to observe the experience of individuals who make up an organization or carry out a process. Social abstractions can be understood through the experiences of the individuals who work and live upon which the abstractions are built (Ferrarotti, 1981). For instance, despite a great deal of research on B2B issues, very little has involved the perspective of the retailers, managers, consultants, advertisers, agents, corporate buyers, employees, salespeople, stakeholders, product designers, and customer service representatives, whose individual and collective experience constitutes how the market comes to understand these issues.

A researcher who wants to understand the dynamics of contemporary B2B market elements may decide to examine personal and institutional documents, make observations, explore history, conduct experiments and distribute questionnaires. If, however, the researcher's goal is to understand the meaning participants make of their personal and professional experience, then interviewing provides a more effective way of inquiry.

The fitness of a research method depends on the intention of the research and the questions being asked (Locke, 1989). For a question such as "How do managers behave in this company?", participant observation might be adequate. If the question is "How does the marketing orientation of a company correlate with overall management attitude?" then a survey may be appropriate. If there is interest in understanding whether a new product design affects corporate procurement policies, then a quasi-experimental, controlled study might be effective. However, research interests are not always so precise. In many cases, there are multiple levels and as a result, multiple methods may need to be in use.

Phenomenological ethnographic interviewing enables an understanding of participants' thought processes, values, aspirations, and professional and life stories in context. Indepth interviewing leads to a more conscious awareness of the power of the social and organizational context of people's experience. Interviewing provides a deeper understanding of the issues, structures, processes, and policies that permeate participants' stories. It gives a fuller appreciation of the complexities and difficulties of change. In-depth interviewing is an approach which attempts to study the "lived experience" (Seidman, 1998), or the "LLife-world,' [...] the world as participants immediately experience it pre-reflectively rather than as they conceptualize, categorize, or reflect on it' (Schütz and Luckmann, 1973; Husserl, 1982).

The purpose of in-depth interviewing is to explore the experience of others and the meaning they make of that experience (Seidman, 1998). Interviews are especially beneficial when motivated to provide "thick descriptions" (Geertz, 1973; Sanday, 1979, Woodside and Wilson, 2003), when the main objective is to achieve deep understanding of 
participant thought paths and decisions. In order to distill a deeper meaning, the observer needs to understand the behavior in context. A basic assumption in in-depth interviewing research is that the meaning people make of their experience affects the way they carry out that experience. This is especially important in a B2B context. Observing managers only provides access to their behavior. Having them fill in surveys restricts their ability to both provide personal input and make meaning of their experiences. However, interviewing allows us to put their behavior in context and to understand their actions.

Some marketing questions are best addressed in a narrative form. Consider an interest in learning what it is like for a brand manager to perform her job, what her experience is, and what meaning she makes of that experience: Schutz (1967) defines this type of understanding as "subjective understanding", exploring the subject's perspective. This type of information may be collected by interviewing.

The method called interviewing covers a wide array of practices. At one end of the continuum are tightly structured formats, survey interviews with preset, standardized, normally closed questions. At the other end, are open-ended, unstructured, anthropological interviews that some (e.g. Spradley, 1979) describe as friendly conversations. We propose an adaptation to a marketing context of what Seidman (1998) calls in-depth, phenomenologically based interviewing. The method combines life-history interviewing (Bertaux, 1981) and focused, in-depth interviewing informed by assumptions drawn from phenomenology, specifically from Alfred Schutz (1967).

We prefer an interview approach that consists of a combination of theoretical positions, where interviewers for the most part use open-ended questions. Their major task is to build upon and explore the responses of participants to the interviewer's questions. The goal is to have participants reconstruct their experiences relevant to the topic. This method is suitable to almost any issue involving the experience of contemporary people (Seidman, 1998), and seems the most appropriate for B2B studies.

Creswell (1998) describes the procedure that is followed in a phenomenological approach to be undertaken in a natural setting where the researcher is an instrument of data collection who gathers words or pictures, analyzes them inductively, focuses on the meaning of participants, and describes a process that is expressive and persuasive in language (p. 14).

Creswell (1998) presents the procedure in a phenomenological ethnography as follows:

1 The researcher begins (the study) with a full description of his or her own experience of the phenomenon (p. 147).

2 The researcher then finds statements (in the interviews) about how individuals are experiencing the topic, lists out these significant statements (horizonalization of the data) and treats each statement as having equal worth, and works to develop a list of non-repetitive, non-overlapping statements (p. 147).

3 These statements are then grouped into "meaning units": the researcher lists these units, and he or she writes a description of the "textures" (textural description) of the experience - what happened - including verbatim examples (p. 150).

4 The researcher next reflects on his or her own description and uses imaginative variation or structural description, seeking all possible meanings and divergent perspectives, varying the frames of reference about the phenomenon, and constructing a description of how the phenomenon was experienced (p. 150).

5 The researcher then constructs an overall description of the meaning and the essence of the experience (p. 150).

6 This process is followed first for the researcher's account of the experience and then for that of each participant. After this, a "composite" description is written (p. 150).

Interestingly, the above process overlooks the crucial step of data collection and conducting interviews. It is for this reason that we found it necessary to modify Seidman's (1998) Three Interview Series Model utilizing Van Manen's (1991) conceptualization of hermeneutic-phenomenology to offer a structure that provides their practicality, coherence, and sense of creativity and their structured forms. Our approach, not unlike Seidman's (1998), is one which favors the specific articulation and importance of context; the need for the development of creative approaches and procedures when implementing research studies, (which should be uniquely suited to both the project and the individual researcher); and an understanding and awareness of "self" within the context of the study limitations.

\section{The three-stage interview}

Seidman's model of in-depth, phenomenological interviewing involves conducting a series of three separate interviews with each participant. Schuman (1982) designed the series of three interviews, which allows the interviewer and participant to investigate the experience and to place it in context. The first interview establishes the context of the participants' experience. The second allows participants to reconstruct the details of their experience within the context. The third interview extracts participants to reflections on the meaning they associate with the experience. For practical issues such as accessibility and time constraints, we have adapted the structure to a single interview whose stages are loosely structured around three main issues ("How did you get here?", "What is it like being you?", "What meaning do you make of it?") within the contextual subject being researched. Understanding context is essential to exploring the meaning of an experience (Patton, 1989). Participants' behavior becomes meaningful and understandable when placed in the context of their personal and professional lives and the lives of those around them.

\section{Interview stage 1: focused life history in context: "How did you get here?"}

In the first stage, the task is to put the participant's experience in context. This is done by asking the interviewee to relate as much as possible about him or herself in light of the topic. Within the context of their life history, avoid asking "Why did you become a ... [whatever the subject may be]?". Instead, ask how they came to be in their present contextual position. By answering "how?" participants reconstruct a variety of constitutive events (Seidman, 1998) in their past experience that place their position in the subject of interest within the context of their lives. The first interview stage serves a secondary purpose of enabling the hermeneutic meaningmaking within the participant. Especially in B2B contexts, where the participant is typically in her office and work surroundings, the "buy-in" of the situation is crucial for both participants and researchers. 
Interview stage 2: the actual experience: "What is it like being you?"

The purpose of the second stage is to focus on the specific details of the participants' present experience in the topic area of the study. Participants are asked to reconstruct these details. Participants are not asked for opinions but rather the details of their experience, participants might be asked to reconstruct a day in the context of the subject of interest. It is this second stage where the researcher gains the most insight into the participants' lived experience. As informative as the academic and extant literatures are, it is to be expected that this stage of the interview will expose new elements that are participant-specific.

\section{Interview stage 3: reflection on the meaning: "What} does it mean to you?"

In the third stage, participants are asked to reflect on the meaning of their experience. Because reflection clarifies and deepens understanding, participants often will provide deeper insights into the reasons for their decisions and actions than expressed earlier. This permits participants to learn what they really believe and feel related to the topics covered in the study (Wilson and Woodside, 2001). The question of "meaning" is not one of satisfaction or reward; rather, it addresses the intellectual and emotional connections between the participants' involvement in the research subject and life. The question might be phrased, "Given what you have said about your life before you became a creative director in an advertising agency and given what you have said about being one now, how do you understand being one in your personal and professional life? What sense does it make to you?". This question may take a future orientation; for example, "Given what you have reconstructed, what do you see yourself doing in the future?". Making sense requires that the participants look at how the factors in their lives interacted to bring them to their present situation (Seidman, 1998). It also requires that they look at their present experience in detail and within the context in which it occurs. The combination of exploring the past to clarify the events that led participants to where they are now, and describing the concrete details of their present experience, establishes conditions for reflecting upon what they are now doing in their lives. The third stage can be productive only if the foundation for it has been established in the first two.

Even though it is in the third stage that researchers focus on, the participants' understanding of their experience is reflected in all three stages. The process of putting experience into language is a meaning-making process (Vygotsky, 1987). When participants are asked to reconstruct details of their experience, they are selecting events from their past and imparting meaning to them in interview stage 3. Focus is given to the research question in context, and the process of making meaning becomes the center of attention.

\section{Length of interviews}

To accomplish the purpose of each of the three stages, Schuman (1982) used a 90-minute format. An hour carries with it the consciousness of a standard unit of time, two hours seems too long to sit at one time. Given that the purpose of this approach is to have the participants reconstruct their experience, put it in the context of their lives, and reflect on its meaning, anything shorter than 90 minutes seems too short. It is important that the length of time be decided before the interview begins.

The participants have a stake in the time allocation. Especially in a B2B study, these are busy people who must know how to schedule their lives. An open-ended time period can produce undue anxiety (Seidman, 1998). At times it may be appealing to go beyond the 90 minutes as the participant addresses interesting issues. Although one might gain new insights by going beyond the agreed time, usually a situation of diminishing returns sets in.

Limiting interview time helps interviewers sharpen their skills. If interviewers are dealing with a large number of participants, they need to schedule their interviews so that they can finish one and go on to the next. As they begin to work with the immense amount of material that is generated in in-depth interviews, they will appreciate having allotted a limited amount of time to each (Seidman, 1998).

\section{Validity and reliability}

Every aspect of the structure, process, and practice of interviewing can be directed toward the goal of minimizing the interaction effect between researcher and participant. Interaction between data gatherers and participants is inherent in the nature of interviewing. It is also inherent in most other research methodologies, despite the sophisticated measures developed to control for it (Campbell and Stanley, 1963). One major difference between qualitative and quantitative approaches is that researchers address the role of the instrument, the human interviewer. Rather than view the interaction as a negative, Seidman (1998) states that the interviewer can be a smart, adaptable, flexible instrument, able to respond to situations with skill, tact, and understanding. Only by recognizing that interaction and affirming its possibilities, can interviewers use their skills to minimize the distortion (Patton, 1989) that can occur. The three-stage interview structure incorporates features that boost validity. It places participants' comments in context, reduces opportunities for idiosyncrasies and checks for internal consistency. By interviewing a number of participants, experiences can be compared and connected.

\section{Hermeneutic data collection: interviewing techniques}

The ability to interview is not innate. Researchers can learn techniques and skills of interviewing. The following is a compilation of "best practices" from Seidman (1998), McCracken (1988), and Wolcott (1981). Interviewers can keep track of how well they are following these guidelines by listening to the interview tapes and reviewing the transcripts. This will ensure a continuous improvement in their skills.

\section{Listen more, talk less}

Listening is the most important skill in interviewing. Interviewers must listen on at least three levels. First, they must listen to what the participant is saying. They must concentrate on the substance to make sure that they understand it and evaluate whether what they are hearing is as detailed and complete as they would like it to be. They must concentrate so that they internalize what participants say.

On a second level, interviewers must listen for what George Steiner (1978) calls "inner voice". An outer, or public, voice 
always reflects an awareness of the audience. It is guarded, a voice that participants would use if they were talking to a large audience. Interviewers need to search for ways to get to the inner voice. By taking participants' language seriously, without making them feel defensive about it, interviewers can promote a level of contemplation more characteristic of the inner voice.

On a third level, interviewers must listen while remaining aware of the process as well as the substance. They must be conscious of time, aware of the flow and attentive to the purpose. They must also be sensitive to the participant's energy level and any nonverbal cues he or she may be offering. Interviewers must stay alert for cues about how to move the interview forward as necessary.

This type of active listening (Seidman, 1998) requires concentration and focus beyond what we usually do in everyday life. It requires that we restrict our normal instinct to talk, but be ready to provide a directional correction when it is needed.

Active listening is facilitated with tape-recordings and field notes (Wolcott, 1990). Working notes help interviewers concentrate on what the participant is saying. They help keep interviewers from interrupting. A good way to appraise listening skills is to transcribe an interview tape. If the interviewer is listening well, his part will be short among the longer paragraphs of the participant's responses.

Finally, ask only real questions. A real question is one which the interviewer does not already know or anticipate the reply. Rather than ask questions that have anticipated responses, it is recommended that the interviewer make a statement and then ask the participant to react.

\section{Follow-up and clarification questions}

When interviewers talk in an interview, they usually ask questions. The key to asking questions is to let them follow from what the participant is saying (Seidman, 1998). Although the interviewer comes with a basic question that establishes the focus of the interview, the researcher also is responsible for asking follow-ups, asking for clarifications, and to move the interview forward by building on what the participant has begun to share.

It is hard work to understand everything. Sometimes the context or a reference is not clear. In everyday conversation, we can let some things slide, but in interviewing such sliding undermines the process. One question establishes the context for the next. Not having understood something in an early stage, might cause the interviewer to miss the significance of something said later. In addition, asking for clarification shows that the interviewer is listening.

It is important to understand experiences in the context of time. A question like "Can you tell me again when that happened?" is reasonable. Use the word again, to suggest that you were just not attentive enough the first time around. Interviewers should ask questions when discussion seems incomplete or vague.

Most importantly, avoid interrupting participants when they are talking. While the participant continues talking, write down the key concept and follow up later, when doing so will not interrupt the participant's storyline.

\section{Avoid leading questions}

A leading question is one that influences the direction the response will take. Sometimes the lead is in the intonation. Sometimes it is in the wording, or the syntax, as when an interviewer asks, "Did you really mean to do that?". Sometimes the lead is in the conclusion implied by the question.

\section{Ask open-ended questions}

An open-ended question establishes the area to be explored while allowing participants to take any direction they want. It does not suppose an answer. There are at least two types of open-ended questions that are relevant. One is what Spradley (1979) calls the "grand tour" question (pp. 86-7), in which the interviewer asks the participant to reconstruct a significant segment of an experience. For example, in interviewing a salesperson, an interviewer might say "Take me through a day in your job". There is also the mini-tour, in which the interviewer asks the participant to reconstruct the details of a more limited time span of a particular experience. For example, an interviewer might ask a participant to talk about a particular selling experience.

A second type of open-ended question focuses more on the subjective experience of the participant than on the external structure. A participant might begin to talk about her experience in a sales negotiation. After asking her what happened, the interviewer might ask her to talk about what that experience was like for her. When interested in understanding the participant's subjective experience, interviewers should often try asking the question, "What was that like for you?". As Schutz (1967) indicated, it is not possible to experience what the participant experienced. The closest we can come is to ask the metaphorical question implied in the word "like". When interviewers ask what something was like for participants, they are giving them the opportunity to reconstruct their experience according to their own sense of what was important, unguided by the interviewer (Yow, 1994).

\section{Ebbs, flows, and focus}

Keep participants focused on the subject of the interview. If they start discussing experiences out of sequence, guide them back to the topics of the current interview. The interviewer must avoid a power struggle, but exercise enough control so that participants respect the structure and individual purpose of each of the three stages. Throughout the interview stages, especially in the first two, ask for concrete details of a participant's experience before exploring attitudes and opinions. The concrete details constitute the experience, the foundation of the interview.

Ebbs and flows in interviews are natural. In-depth interviewing may surprise participants because they may not have had the opportunity to talk at length to someone outside their social circle. As a result, they may become so engaged in the first stage that they share personal details and feel vulnerable (Spradley, 1979). Interviewers find that participants may retract at the second stage and be less willing to share as much as before. The researcher must be careful not to press too hard for the type of sharing they experienced before. The third stage allows participants to find a zone of sharing within which they are comfortable, and resolve the issue for themselves.

\section{Participant reconstructing versus remembering}

Avoid asking participants to rely on their memories. As soon as interviewers ask if people remember something, impediments to memory pop up (Tagg, 1985). Ask participants not to remember their experience but rather to 
reconstruct it. Ask directly "What happened?" or "What was your first encounter with that supplier like?" instead of "Do you remember what your first encounter with that supplier was like?". Interviewers can assume that participants will be able to reconstruct their experience and thus avoid many of the possible impediments to memory. In a way, all recall is reconstruction (Thelen, 1989). In interviewing, it is better to strive for reconstruction as directly as possible.

\section{Use an interview guide cautiously}

Some forms of interviewing depend on an interview guide (Yow, 1994.) The interviewer arrives with preset questions to which she wants answers or about which she wants to gather data. This is not appropriate for in-depth interviewing, which is designed to explore experiences and the meanings attached to them. The questions most used in an in-depth interview follow from what the participant has said. Nonetheless, indepth interviewers may want to develop an interviewing guide. The basic structure of the interview is the question that establishes the focus of each stage in the interview. However, interviewers never come into an interview situation as clean slates. They have interests, or they would not have chosen the research topic they did. In addition, some participants will require more prompting than others to go forward in the reconstruction of their experience. Moreover, over the course of a number of interviews, the interviewer may notice that several participants have highlighted a specific issue, and the interviewer may want to know how other participants have responded to that issue. If interviewers decide to use an interviewing guide, they must avoid manipulating their participants to respond to it. Interviewers should ask questions that reflect areas of interest to them in an open and direct way, possibly acknowledging that the question comes more from their own interest than from what the participant has said. Interviewers must try to avoid imposing their own interests on the experience of the participants. Interviewers working with an interview guide must allow for the possibility that what may interest them or other participants may be of little interest to the person being interviewed. Interview guides are useful but must be used with caution.

\section{Silence}

Interviewers sometimes get impatient and uncomfortable with silence. Be patient; give the participant time to reflect. However too much silence leads to uneasiness so as in other aspects of interviewing, there is a delicate balance between jumping in too soon with a question and waiting too long in silence. It is important to give your participant space to think, reflect, and add to what he or she has said (Seidman, 1998). This may take a second or two for some participants and 30 seconds for others.

\section{Conclusion and final comments}

The truly effective question flows from an interviewer's concentrated listening, and purpose in moving forward. Sometimes an important question will start out as an imprecise instinct which takes time to develop. Sometimes the effective question reflects the interviewer's own groping for understanding. Effective questioning is bound by context. The most important personal characteristic interviewers must have is a legitimate interest in other people and their stories.
Seidman (1998) stresses the importance of adhering to the three-part structure. Each stage serves a purpose both by itself and within the series. Sometimes, in the first stage, a participant may start to tell an interesting story about his or her present situation; but that is the focus of the second stage. It is tempting, because the information may be interesting, to pursue the participant's lead and forsake the structure of the interview. To do so, however, can wear down the focus of each stage and the interviewer's sense of purpose. Each stage comprises a large number of decisions that the interviewer must make. The open-ended, in-depth inquiry is best carried out in a structure that allows both the participant and the interviewer to maintain a sense of focus of each interview stage in the series. Each stage provides a foundation of detail that helps illumine the next. Taking advantage of the interactive and cumulative nature of the sequence of the stages requires that interviewers stick to the purpose of each. There is a logic to the stages, and to lose control of their direction is to lose the power of that logic and the benefit from it (Seidman, 1998). In the process of implementing the three stage interview, the interviewer must maintain a balance between providing enough openness for the participants to tell their stories and enough focus to allow the interview structure to work (McCracken, 1988). As much as you try, maintaining the structure might not always be possible. The next section discusses possible alternatives in such situations.

Researchers will have reasons for exploring alternatives to the structure and procedures that we describe. As long as a structure is maintained that allows participants to reconstruct and reflect upon their experience within the context of their lives, alterations to the three-stage interview structure and the duration of interviews can certainly be explored. Too extreme a bending of the form may result in failure to realize the original intent. As yet, there are no absolutes in the world of interviewing (Seidman, 1998).

Every research method has its limits and its strengths. Indepth interviewing leads to a deeper understanding and appreciation of the intricacies and coherence of people's experiences. It leads to a more conscious awareness of environmental context. Most important, researchers gain an appreciation for the value of story telling and for the participants who live the stories.

The narratives we shape from the participants are necessarily limited. Their lives go on; our presentations of them are framed and reified. As illuminating as in-depth interviews can be we still have to allow considerable tolerance for uncertainty.

\section{References}

Arnold, S.J. and Fischer, R. (1994), "Hermeneutics and consumer research", fournal of Consumer Research, Vol. 21, June, pp. 55-70.

Bertaux, D. (Ed.) (1981), Biography and Society: The Life History Approach in the Social Sciences, Sage Publications, Beverly Hills, CA.

Campbell, D. and Stanley, J. (1963), "Experimental and quasi-experimental design for research in teaching", in Gage, N.L. (Ed.), Handbook of Research on Teaching, Rand McNally, Chicago, IL, pp. 171-246.

Colby, B. (1996), "Cognitive anthropology", in Levinson, D. and Ember, M. (Eds), Encyclopedia of Cultural Anthropology, Vol. 1, Henry Holt \& Co., New York, NY, pp. 209-14. 
Creswell, J.W. (1998), Qualitative Inquiry and Research Design: Choosing among Five Traditions, Sage Publications, Thousand Oaks, CA.

D'Andrade, R. (1981), “The cultural part of cognition", Cognitive Science, Vol. 5, pp. 179-95.

Dervin, B. and Clark, C. (1987), ASQ: Alternative Tools for Information Need and Accountability Assessments by Libraries, published by Peninsula Library Systems for the California State Library, Sacramento, CA.

Ferrarotti, F. (1981), "On the autonomy of the biographical method", in Bertaux, D. (Ed.), Biography and Society: The Life History Approach in the Social Sciences, Sage Publications, Beverly Hills, CA, pp. 19-27.

Fournier, S. and Mick, D.G. (1999), "Rediscovering satisfaction", Fournal of Marketing, Vol. 63, pp. 5-23.

Geertz, C. (1973), "Thick description: toward an interpretive theory of culture", The Interpretation of Cultures, Basic Books, New York, NY, pp. 3-30.

Grayson, D.K. (1973), "On the methodology of faunal analysis”, American Antiquity, Vol. 38 No. 4, pp. 432-9.

Hunt, S.D. (2002), Foundations of Marketing Theory: Toward a General Theory of Marketing, M.E. Sharpe, Armonk, NY.

Husserl, E.G.A. (1982), Ideas Pertaining to a Pure Phenomenology and to A Phenomenological Philosophy: First Book, (trans, by Kersten, F.), Kluwer, Dordrecht.

Locke, L. (1989), "Qualitative research as a form of scientific inquiry in sport and physical education”, Research Quarterly for Exercise and Sport, Vol. 60 No. 1, pp. 1-20.

McCracken, G. (1988), The Long Interview, Sage Publications, Beverly Hills, CA.

Patton, M.Q. (1989), Qualitative Evaluation Methods, 10th ed., Sage Publications, Beverly Hills, CA.

Sanday, P.R. (1979), "The ethnographic paradigm(s)", Administrative Science Quarterly, Vol. 24 No. 4, pp. 527-38.

Schuman, D. (1982), Policy Analysis, Education, and Everyday Life, Heath, Lexington, MA.

Schutz, A. (1967), The Phenomenology of the Social World, (trans. by Walsh, G. and Lenhert, F.), Northwestern University Press, Chicago, IL.

Schütz, A. and Luckmann, T. (1973), The Structures of the Life-world, Northwestern University Press, Evanston, IL.

Seidman, I. (1998), Interviewing as Qualitative Research, Teachers College Press, New York, NY.

Spiegelberg, H. (1982), The Phenomenological Movement, Martinus Nijhoff, Dordrecht.

Spradley, J.P. (1979), The Ethnographic Interview, Holt, Rinehart, and Winston, New York, NY.

Starbuck, W.H. (1982), "Congealing oil: inventing ideologies to justify acting ideologies out", Fournal of Management Studies, Vol. 19 No. 1, pp. 3-27.

Starkey, K. and Madan, P. (2001), "Bridging the relevance gap: aligning stakeholders in the future of management research", British fournal of Management, Vol. 12, Special Issue, pp. S3-S26.

Steiner, G. (1978), "The distribution of discourse", On Difficulty and Other Essays, Oxford University Press, New York, NY, pp. 61-94.
Strati, A. (1998), "Organizational symbolism as a social construction: a perspective from the sociology of knowledge", Human Relations, Vol. 51 No. 11, pp. 1379-402.

Strauss, C. and Quinn, N. (1997), A Cognitive Theory of Cultural Meaning, Cambridge University Press, Cambridge.

Sutcliffe, K.M. and Huber, G.P. (1998), "Firm and industry as determinants of executive perceptions of the environment", Strategic Management fournal, Vol. 19 No. 8, pp. 793-807.

Tagg, S.K. (1985), "Life story interviews and their interpretations", in Brenner, M., Brown, J. and Canter, D. (Eds), The Research Interview: Uses and Approaches, Academic Press, London, pp. 163-99.

Thelen, D. (1989), “A new approach to understanding human memory offers a solution to the crisis in the study of history", The Chronicle of Higher Education, September 27, pp. B1, B3.

Tyler, S. (1969) in Tyler, S. (Ed.), Cognitive Anthropology, Holt, Rinehart and Winston, New York, NY, pp. 1-23.

Van Manen, M. (1990), Researching Lived Experience: Human Science for an Action Sensitive Pedagogy, Althouse Press, London (Ontario).

Van Manen, M. (1991), The Tact of Teaching: The Meaning of Pedagogical Thoughtfulness, State University of New York Press, Albany, NY/Althouse Press, London (Ontario).

Vygotsky, L. (1987) in Kozulin, A. (Ed.), Thought and Language, MIT Press, Cambridge, MA.

Weick, K. (1979), The Social Psychology of Organizing, 2nd ed., Addison-Wesley, Reading, MA.

Weick, K.E. (2001), "Gapping the relevance bridge: fashions meet fundamentals in management research", British Fournal of Management, Vol. 12, pp. S71-5.

Wilson, E.J. and Woodside, A.G. (2001), "Executive and consumer decision processes: increasing useful sensemaking by identifying similarities and departures", fournal of Business E Industrial Marketing, Vol. 16 No. 5, pp. 401-14.

Wolcott, H.F. (1981), "Home and away: personal contrasts in ethnographic style", in Messerschmidt, D.A. (Ed.), Anthropologists at Home in North America, Methods and Issues in the Study of One's Own Society, Cambridge University Press, New York, NY, pp. 255-65.

Wolcott, H.F. (1990), Writing up Qualitative Research, Sage Publications, Newbury Park, CA.

Woodside, A.G. and Wilson, E.J. (2003), "Case study research methods for theory building", Fournal of Business E Industrial Marketing, Vol. 18 Nos 6/7, pp. 493-508.

Yow, V.R. (1994), Recording Oral History: A Practical Guide for Social Scientists, Sage Publications, Thousand Oaks, CA.

Zaner, R.M. and Ihde, D. (1973), Phenomenology and Existentialism, Putnam, New York, NY. 